\title{
Interações, trilhas e caminhos de uma cidade em fluxo: etnografia na Cracolândia
}

DOI

http://DX.DOI.ORG/10.11606/ 1678-9857.RA.2021.184481

\section{Ygor Diego Delgado Alves}

Universidade Federal de São Paulo / São Paulo, SP, Brasil ygordiegodelgadoalves@gmail.com ORCID: http://orcid.org/0000-0002-6730-3255

\section{Pedro Paulo Gomes Pereira}

Universidade Federal de São Paulo/São Paulo, SP, Brasil pedropaulopereira@gmail.com

ORCID: https://orcid.org/0000-0002-0298-2138

RESUMO

PALAVRAS-CHAVE

Cracolândia, etnografia, fluxo, materiais, caminhos

o que as atrai para o "fluxo". Esta é a tarefa que procuramos empreender neste artigo. Para tal, empreendemos uma pesquisa de cunho etnográfico que nos aproximou da imaginação conceitual e das ações das próprias pessoas que habitam essas aglomerações urbanas. Pudemos então indagar sobre o que nos conta a categoria "fluxo", sobre as relações ali estabelecidas que tornam aquele espaço habitável. Concluímos que no "fluxo", e talvez isto o torne atraente, não há fato consumado, como um objeto, mas, acontecimentos, entrelaçamentos passageiros de materiais em movimento, coisas que, à medida que a vida prossegue, demandam esforço incessante para se manterem íntegras face aos ataques do meio.

Interactions, trails and paths of a city in flux: ethnography of Cracolândia

ABSTRACT An anthropology of Cracolândia ought to be able to link paths around the "flow" with the trajectories made possible through encounters of materials and people. Little has been said about what moves these people to form sui generis groups, and about what attracts them to the "flow." It is this task that we aim to undertake in this article. To this end, we undertook an ethnographic research that brought us closer to the conceptual imagination and the actions of the people who inhabit these urban agglomerations. We were then able to inquire about what the "flow" category tells us, about the relationships established there that make that space habitable. We conclude that in the "flow", and perhaps this makes it attractive, there is no consummate fact, as an object, but, events, fleeting interlacing of materials in motion, things that, as life goes on, demand unceasing effort to maintain themselves intact in the face of attacks from the middle.

KEYWORDS Cracolândia, ethnography, flow, materials, paths 


\section{INTRODUÇÃO}

Localizada na região central da cidade de São Paulo, a Cracolândia é uma imensa cena de uso de crack, que chegou a possuir um "fluxo" de mil e quinhentos frequentadores diários (PMSP, 2015). Tal agrupamento urbano foi objeto de importantes pesquisas etnográficas anteriores, que destacaram os mais variados enfoques, desde as relações entre o Estado, o legal e o ilegal (Adorno et. al., 2013; Da Silva e Adorno, 2013; Rui, 2012), passando pelas relações entre saúde e ambiente (Costa, 2015), pela territorialidade e suas conexões com a cidade (Frúgoli Júnior e Cavalcanti, 2013; Rui, 2014) e as estratégias de autocontrole e autocuidado (Adorno et. al., 2014; Raupp e Adorno, 2015), até as práticas de lazer e resistência (Aderaldo e Fazzioni, 2012; Calil, 2016). Além da Cracolândia, espalham-se pela cidade muitas "biqueiras", locais de venda e, por vezes, também de uso, com suas diversas e movimentadas rodas de crack, que se caracterizam pelo consumo coletivo de substâncias psicoativas (Mercante, 2015).

Não obstante essa rica literatura, o espaço de uso de crack vem sendo caracterizado, na mídia, com imagens negativas e associado a doenças, desespero e violências. Um enclave social, talvez um dos maiores do Brasil, com um amontoado de "zumbis" (Alves, 2017). Muitos argumentam que tal enclave se origina, única e exclusivamente, da pobreza ou da "fissura", da dependência imediata e inexpugnável à droga. Todavia, a experiência etnográfica foi nos levando para outras indagações. A etnografia buscou escapar das visões externas às experiências dos usuários de crack e, como nos ensina a boa antropologia, procurar uma aproximação às formas usadas pelos próprios consumidores da droga para se definir e para construir o "fluxo". Deparamo-nos, então, com conceitos e práticas que formam uma visão do "fluxo" distantes daqueles que estávamos acostumados a ouvir.

"Fluxo" surgiu então como uma categoria usada pelos próprios usuários de crack para designar os movimentos e percursos em torno do consumo da droga e para definir a aglomeração humana de grande densidade em torno do crack. No entanto, pouco se fala sobre o que move essas pessoas para a formação de conjuntos tão sui generis - sobre o que as atrai para o "fluxo". É a tarefa que procuraremos empreender neste artigo.

O que nos conta a categoria "fluxo"? Entendendo seu potencial de atração, fomos levados, ainda, a questionar: quais relações constituídas no "fluxo" possibilitam que se habite esse espaço? Da mesma forma: que relações e forças se estabeleciam para que as rodas de crack se espalhassem pelo bairro da Luz? Essas questões foram surgindo no fazer etnográfico que nos aproximou da imaginação conceitual e das ações das próprias pessoas que habitam essas aglomerações urbanas.

Assim, os craqueiros, ao se movimentarem em torno das trocas constantes no interior do "fluxo", expõem-se à contínua transformação, por meio do consumo do crack, dos ajustes frequentes na parafernália de uso e pelos processos de degradação 
a que estão sujeitas suas coisas pela ação da chuva, do vento e do sol. Como seria possível enfrentar tais forças? Quais ações e vias imaginativas seriam capazes de misturar e fundir materiais heterogêneos na geração das coisas e de práticas que enfrentassem as adversidades da vida? Enfim, estamos indagando sobre o caráter experimental da vida cotidiana (Ingold, 2015). Essas perguntas podem nos levar a compreender as vias imaginativas que um craqueiro improvisa à medida que a vida prossegue-como ele, por exemplo, projeta e constrói uma habitação que não ignora o contexto da cidade e cujo destinatário é ele mesmo - uma utopia urbana materializada na moradia de rua.

Com esse propósito, este artigo está dividido da seguinte forma: primeiro, discorremos sobre a etnografia realizada e as particularidades de uma observação em um contexto que apresenta desafios. Em seguida, nos aproximamos de uma roda de crack, abordando uma pequena cena de uso. Depois, descrevemos o "fluxo", mostrando como, em seu interior, pessoas se relacionam com materiais em contínua transformação, entendendo "fluxo" também como categoria tão importante como outras da antropologia urbana. Posteriormente, mostramos como a prática de habitar a Cracolândia ou o "fluxo" faz dos craqueiros parte de um ambiente que vai se fazendo cada vez mais parte deles. Por último, vamos sugerir que, na "maloca", construção de certo modo efêmera destinada a proporcionar um mínimo de abrigo e intimidade, revela-se uma utopia urbana, oposta à homogeneização universalista e funcional da cidade.

\section{ETNOGRAFIA NA CRACOLÂNDIA}

Este artigo surgiu de pesquisas na região paulistana conhecida como Cracolândia. De início, o primeiro autor deste texto ali realizou uma etnografia por dois anos. Em seguida, procurando compreender as políticas públicas para crack, realizamos em conjunto uma pesquisa, de fevereiro de 2016 a julho de 2018, por meio de observação participante, entrevistas e acompanhamento da vida cotidiana dos profissionais de saúde e usuários de crack. Assim, este é um trabalho no qual os autores já vêm dialogando há mais de quatro anos e que propiciou que ambos participassem da redação, concepção e revisão final do artigo - o que pode ser percebido por formas verbais e pronominais características da primeira pessoa do plural.

As experiências etnográficas nos possibilitaram conviver com pessoas que usavam crack nas ruas do centro da capital paulista e com os profissionais que trabalhavam na Cracolândia. Acabamos por ter uma inserção de proximidade, que nos remeteu às vivenciadas pelos nossos antecessores e contemporâneos brasileiros na pesquisa sobre o uso de drogas, tais como Fernandez (2007), MacRae e Simões (2000), Malheiro $(2012,2013)$ e Velho (1975), entre outros, que foram a campo e conviveram com as pessoas que usavam drogas tornadas ilícitas, ou seja, que fizeram 
etnografia do uso destas drogas. Também foi o caso dos estudos de Bourgois (2006), com vendedores de crack, e de Bourgois e Schonberg (2009), realizado entre usuários de heroína.

Essa experiência etnográfica e as perguntas que iam surgindo em campo nos levaram à proposta teórico-metodológica de Tim Ingold (1991), ou seja, uma busca de retorno do sujeito e da prática. Dessa maneira, Ingold defende uma totalidade indivisível entre organismo e ambiente, enfocando a centralidade da habilidade prática; há aqui a presunção da indissociabilidade mente/corpo, visível nos estudos da ação e da percepção, dos sentidos, da linguagem, da tecnologia e da arte, para compreensão das formas de engajamento e de desenvolvimento no mundo (Ingold, 2002a, p. 289-419; Silva, 2011). As capacidades de pensar e agir surgem, assim, como propriedades emergentes de um sistema total de desenvolvimento constituído por meio da disposição da pessoa para estar, desde o princípio, dentro de um campo de relacionamentos com o mundo e com outras pessoas (Ingold, 2003, p. 20).

Uma etnografia na Cracolândia tem, no entanto, suas especificidades. Ali, talvez mais que em outros lugares, quanto mais vezes se é visto, menos preocupação se causa, até se tornar despercebido. Porém, sempre se faz necessária uma primeira abordagem, um momento de chegada. Em um ambiente de atividade proibida e perseguida, como o do uso do crack, devido ao constante risco de investidas punitivas por parte da polícia, mesmo o desconhecido apresentado na companhia de antigo frequentador, como foi nosso caso, será alvo da inquirição a respeito de suas credenciais para lá estar. As primeiras incursões ao campo foram realizadas na região do centro de São Paulo conhecida como Cracolândia. Nas tentativas iniciais sequer foi possível chegar ao local. Nesse caso, tivemos que iniciar no reconhecimento dos arredores. Nas primeiras oportunidades de adentrar na cena de uso, observávamos a certa distância, sem conseguir nos deter entre os usuários de crack. A inserção só foi possível após sermos apresentados, por um conhecido em comum, a um consumidor da droga que se dispôs a nos acompanhar por alguns meses, nos anos de 2013 e 2014, nas cenas abertas de uso. Com o conhecimento acumulado sobre o campo e as relações construídas com profissionais que atuam na Cracolândia e com alguns usuários de crack, pudemos retornar em 2016. Nesta ocasião, convivemos novamente no "fluxo", acompanhando o cotidiano das pessoas e pudemos ainda realizar outras entrevistas.

O ofício antropológico propõe a criação de uma narrativa a respeito do outro que parte das relações construídas no campo. Quando se adentra na intimidade de nossos interlocutores (Herzfeld, 1997), como procuramos fazer, certos relacionamentos passam a ser constantemente negociados. O tipo e a profundidade das informações que daí irão surgir dependem e mesmo provêm da qualidade dessas relações. Antes de obter informações a respeito das relações entre nossos interlocutores, construímos relações com eles. É um movimento que vai das relações com eles para o saber sobre as relações entre eles (Strathern, 1999). No próprio fazer etnográfico, 
descobrimos que, quanto mais intensamente afetados fôssemos pelas relações proporcionadas pelo campo e, principalmente, pelas mesmas forças que atuam sobre eles - naquilo que para nós era o campo e que para eles era a vida -, mais nos foi permitido sentir, não a sensação no outro, mas em nós, as consequências de estar na posição do interlocutor (Favret-Saada, 2005). A partir desse encontro, a escrita etnográfica pôde se dar de modo mais profícuo.

Desde o início, contamos com as possibilidades abertas pela presença de nosso interlocutor privilegiado e guia no início da investigação, somadas à disposição em frequentar os locais de uso, os territórios psicotrópicos sob a fumaça constante, no beco, este espaço ao mesmo tempo ponto de mercado e ponto de consumo (Fernandes; Pinto, 2004). Nosso interlocutor privilegiado viabilizou a presença no campo com chances de acompanhar práticas e, certamente, discursos e racionalizações provenientes dos interlocutores, de certa forma mais próximos à condição de, como eles diziam, "parceiros". Das informações colhidas no campo para a escrita etnográfica tivemos de empreender a necessária tarefa de ordenar as coisas (Uriarte, 2012) para possibilitar a leitura por quem não esteve lá, no sentido de narrar nossas experiências com um mínimo de coerência.

Para iniciarmos a narrativa, na próxima seção vamos nos aproximar de uma roda de crack, abordando uma pequena cena de uso. Tal opção deve-se à própria experiência do usuário de crack que, muitas vezes, não chega ao "fluxo" diretamente em seu centro, mas, pouco a pouco, por meio de algumas de suas ramificações espaIhadas pelos bairros da Luz e Bom Retiro.

\section{DA RODA DE CRACK AO FLUXO}

Na segunda década do século XXI, a Cracolândia paulistana passou a se concentrar entre a Estação Júlio Prestes, em um terreno abandonado pelo governo estadual, onde ficava a antiga rodoviária, e o Largo Coração de Jesus, localizado a dois quarteirões, tanto da antiga Rodoviária da Luz, quanto da Estação Júlio Pestes. A Cracolândia chegou a ocupar outros quarteirões do que foi a região da Boca do Lixo e, ainda hoje, possui como que postos avançados pela redondeza. É perfeitamente possível, por exemplo, adquirir crack nos caminhos que levam à Cracolândia ou, mais especificamente, ao "fluxo": a aglomeração com centenas de usuários de crack e que chegou a ter mais de uma dezena de quilos da pedra expostos para a venda, simultaneamente. No Largo General Osório, localizado na Rua Mauá, ao lado da Estação Júlio Prestes, era constante a presença de usuários de crack. O mesmo ocorrendo a uma centena de metros em direção à Rua Brigadeiro Tobias, próximo a uma das entradas da Estação da Luz.

Em 2012, na esquina das ruas Mauá e Brigadeiro Tobias, costumava se formar uma ou duas rodas de crack. Por vezes, um "vapor" (termo utilizado para se referir aos pequenos vendedores da pedra) ficava no local fornecendo droga a usuários 
distintos. Desde aqueles com aparência típica de moradores de rua e frequentadores do "fluxo", até homens e mulheres vestidos como trabalhadores - geralmente de escritório, mas também trabalhadores manuais - que se dirigiam às estações da Luz e Júlio Prestes, além de algumas prostitutas que faziam ponto em frente ao hotel de esquina. Na marquise da Estação da Luz, logo em frente, que era ocupada por profissionais do sexo, algumas das quais também faziam uso de crack, havia a presença constante da polícia militar.

A figura1 evidencia, em 2012, uma profissional do consultório na rua, atendendo em frente ao "vapor" que se encontra de pé, no degrau do estacionamento abandonado, na rua Mauá.

Naquela ocasião, o "vapor" promovia sua droga como "embalada" ou "no plástico" e declarava ser ela melhor que a comercializada no "fluxo", que era vendida "solta". Melhor porque em maior quantidade. Acompanhamos as atividades que transcorriam na

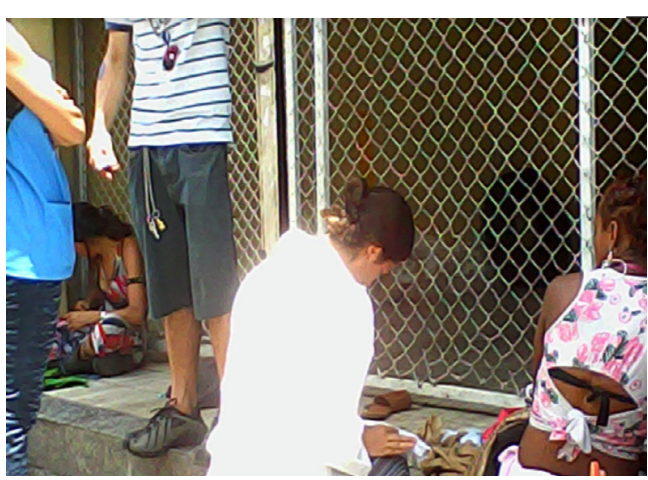
calçada e sem uso do recurso da "maloca" (sobre a qual falaremos com mais detalhes adiante), geralmente construída com lona ou cobertores sobre a calçada, para proporcionar maior intimidade. No máximo, se valiam de um cobertor ou vestimenta para cobrir a cabeça durante o "trago", unidade de consumo da pedra de crack que é dividida em vários "tragos". Chegamos a ser abordados por profissional do Sistema Único de Saúde (SUS), consultório na rua, que fazia perguntas sobre o estado geral de saúde das pessoas, seguindo um questionário. Os pedestres passavam por nós sem dar grande importância ou atenção, em uma atitude francamente blasé (Simmel, 1971), como que indiferentes ao que ocorria ali e absortos no caminho à frente, muitas vezes, rumo à estação de trem.

Em torno do "vapor" formava-se, então, a roda de crack - um contexto psicotrópico, uma situação social densa com pessoas partilhando o mesmo interesse, focadas no consumo da pedra. Os demais transeuntes que não se detêm na roda, em sua grande maioria, não se dão conta dela, não participam desta definição da realidade comum aos que nela interagem com grande homogeneidade. $\mathrm{O}$ tom dominante é de cuidado para não atrair a curiosidade ou olhar de reprovação do "Zé Povinho", ou, ainda, gerar "aproximação" de indesejáveis, como a polícia que fazia plantão a poucos metros. Havia uma participação comum naquele contexto psicotrópico que parecia sobrepujar sua heterogeneidade do ponto de vista de gênero, faixa etária, ocupação laboral e diversidade étnica. Os símbolos compartilhados permitiam ao pedestre que se interessa pelo uso do crack perceber que ali ocorre uma situação de uso da droga.
Figura 1

Consultório de rua e "vapor"

Fonte: Coleção

particular do autor
1 | O termo Zé Povinho resume o ponto de vista do usuário de crack sobre os ocupados transeuntes da capital paulistana, ao se movimentarem pela cidade, envoltos em seus afazeres. 
A linguagem básica comum possibilita certa gramaticalidade, a despeito das idiossincrasias. A roda de cracké um local razoavelmente seguro em que os desempenhos podem corresponder às expectativas de passantes virtualmente desconhecidos, mas que sabem perfeitamente o que esperar de quem esteja na condição, por exemplo, de "vapor".

A roda de crack conta com o comportamento blasé da população, que segue seu caminho indiferente à sua presença que, caso contrário, se destacaria na paisagem. São centenas que passam incólumes por não terem muito a ver com esta droga não pertencente às suas possibilidades de êxtase e de sofrimento. A roda de crack faz parte do campo de possibilidades próprio à cidade grande, onde trajetórias e trilhas podem se cruzar. Permite ao trabalhador que se dirige à estação de trem, no retorno para casa após um dia de labuta, colocar-se sob o efeito empatogênico da pedra. A experiência de usar crack na calçada permite certas interações sociais, possivelmente, difíceis de ocorrerem sem este aglutinador. Travessias sociológicas que possibilitam colocar em contato o funcionário, o "vapor", a prostituta e a moradora de rua. Em nossa pesquisa de campo realizada numa "biqueira" do bairro do Cambuci, em São Paulo, tivemos por guia, em nossa introdução no campo, um engenheiro com pouco menos de cinquenta anos na época e que havia frequentado, em sua carreira de usuário (Becker, 2009), numerosas "biqueiras" pela cidade. Isto lhe proporcionava, segundo ele, "noites extremamente agradáveis" em companhia de moradores(as) de rua com quem mantinha vínculos de amizade há décadas.

$\mathrm{Na}$ "biqueira", com seus usuários de crack e atraindo a presença de frequentadores das mais diversas origens, a noção de fronteira passa a ser relativa. Os consumidores da droga não estão isolados, pois a circulação da pedra de crack insiste em atrair personagens com as trajetórias mais díspares, cada um deles, como nos propôs Simmel (1971), a intersecção de vários mundos. A roda de crack possibilita a troca por meio da "treta" (um circuito de trocas generalizadas de bens e serviços) e a aliança com os "parças" (colegas), ou seja, uma vida social por meio da experiência, onde se faz necessário o reconhecimento de valores e interesses diversos, como os do engenheiro que a frequenta esporadicamente ou do trabalhador que apenas se detém para um "trago"; também dos valores e interesses, grandemente, influenciados pelo tráfico de drogas, do "vapor". O mesmo para os valores e interesses das prostitutas da Estação da Luz que consomem crack e podem ver no usuário eventual um possível cliente.

Esse engenheiro que mencionamos anteriormente desenvolveu capacidades que o permitiam acessar códigos, originalmente ligados à população de rua usuária de crack, possibilitadores de sua participação nas rodas de consumo desta droga. A lógica da hierarquia social não permite o inverso; muito dificilmente usuários de crack moradores de rua poderiam frequentar os ambientes em que se vive como engenheiro. Mesmo assim, a roda de crack permite a coexistência de discursos e visões de mundo díspares: o engenheiro supracitado, por exemplo, gostava de comentar 
sobre aspectos técnicos de sua profissão sob efeito do crack, esta era sua "brisa". Estes códigos e discursos associados ao uso do crack apresentam amplitude sociológica e profundidade histórica. Expressões como "brisa", "fazer a cabeça" e "dar um tapa", por exemplo, possuem um uso que remonta a décadas e podem ter origens em outras esferas do social -como o termo "fazer a cabeça" e em religiões de matriz africana no Brasil. Malgrado essas características, sabemos que o uso do crack e seus códigos e discursos não encontram legitimidade junto à sociedade abrangente. É, assim, alvo de restrições e discriminação, como as perseguições policiais que ocorrem sobre as cenas de uso, transformando o consumo desta droga em atividade semiclandestina, ao contrário do consumo aberto de álcool, quase onipresente nas "biqueiras" paulistanas e no "fluxo", na forma de pequenas embalagens de meio litro de cachaça, que custam o mesmo que um único "trago" de crack. É comum entre os usuários de crack ouvirmos que o álcool serve para baixar a paranoia resultante do consumo constante da pedra. Mas por que não pensarmos que a pedra possa ser o energizador disponível para prolongar o binge (uso de drogas até o esgotamento físico ou de fundos para aquisição) alcoólico? Portanto, é possível se falar em uma maleabilidade entre o mundo aparentemente subterrâneo das drogas tornadas ilícitas e as oficialmente mantidas lícitas e de consumo largamente incentivado, como é o caso do álcool.

Da roda de crack, com os aprendizados e o acúmulo de experiências, o usuário passa, lentamente, a frequentar o "fluxo", espaço com maior poder de atração, quantidade de pessoas e complexidade. O "fluxo" da Cracolândia procura excluir, de muitas formas, os não envolvidos no uso da droga. O paulistano mais dificilmente se aventura a transitar do mundo do trabalho, por exemplo, para o "fluxo", por considerar ser mais fácil dirigir-se a uma roda de crack como a que acabamos de descrever. A "maloca" e o "mocó", esta reentrância no concreto da cidade, são também úteis no sentido de evitar o trauma, o choque provocado no outsider, não usuário, pela visão de consumidores ativos da cocaína fumada. O potencial de transitar por diferentes mundos em São Paulo é distribuído desigualmente. Quem "é do crack" e é morador de rua poderia ser colocado na base desta hierarquia. Além disto, ao se tornar morador da Cracolândia ou frequentador cotidiano do "fluxo", dele se ausentando o mínimo necessário para algum "corre" em busca de fundos para aquisição de crack, sua capacidade de transitar pelos diversos espaços da cidade diminui: deparamo-nos com pessoas há anos sem abandonar a área restrita do "fluxo" (Rui, 2014a). A categoria "corre" geralmente designa o movimento do usuário de crack em busca de fundos, ou seja, "fazer um corre". Também pode significar um estado momentâneo "estou na correria" ou característica pessoal: "Sou correria, mas tô sem um real no bolso" (Clemente, 2006: 27). Esta última acepção, às vezes, está ligada ao pequeno tráfico. Porém, mesmo em movimento, não se encontra mais ancorado na família ou na vizinhança que o expulsou, tampouco em uma organização política ou religiosa. Sua capacidade de acionar códigos associados a contextos e domínios diversos aos da 
rua vai sendo minada. Porém, nem só de negatividade se vive no "fluxo". Na figura 2 temos a imagem do "fluxo" na Alameda Dino Bueno, em 2013.

Cabe aqui uma breve discussão sobre a categoria "fluxo". Trata-se de uma categoria complexa, que envolve movimentos, socialidades, intervenções políticas e elucida os usos sociais do espaço. Quem estuda a antropologia urbana no Brasil se aproxima de outras categorias, tais como circuito e pedaço, entre outras

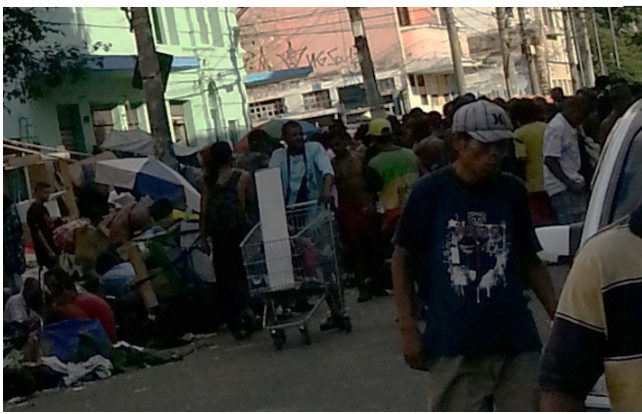

Figura 2

O "fluxo", em 2013, na alameda Dino Bueno Fonte: Coleção particular do autor. (Magnani, 2003, 2008, 2014). Circuito, por exemplo, seria "a configuração espacial, não contígua, produzida pelos trajetos de atores sociais no exercício de algumas de suas práticas, em dado período de tempo" (Magnani, 2014: 9). Pedaço corresponderia a um componente espacial em que se estabelecem redes de relações sociais. Há ainda a categoria "quebrada", usada para definir espaços, territorialidades, sem que sejam necessariamente contíguos ou apenas geograficamente delimitados (Malvasi, 2012). Mas, o que seria "fluxo"?

O "fluxo" é uma aglomeração humana com dezenas ou mesmo centenas de usuários de crack a depender de diversos fatores, desde climáticos, passando pela repressão policial ao tráfico, até a proximidade ou não dos dias de pagamento. A disponibilidade da droga também é fator importante na construção e localização do "fluxo". O usuário está onde há droga e vice-versa. O crack é levado para próximo aos usuários e estes, por sua vez, se dirigem para o local com maior disponibilidade de crack. Aparentemente, próximo ao "fluxo", ou melhor, dentro dele, os "blocos" são mais "bem fechados", termo utilizado para se referir às pedras maiores e com embalagens ainda não violadas. Dentro e fora dele, pode-se adquirir qualquer fração do "bloco" até chegar a doses unitárias, ou seja, suficiente para um "trago". Essas frações da pedra original de crack são trocadas - também os mais diversos bens e serviços - dentro do "circuito da treta", tornando o "fluxo" um local de imensa agitação e até abrindo espaço aos "profissionais da treta" ou indivíduos dedicados a comprar e vender objetos usados e novos. O "fluxo" é essa multiplicidade de materiais, ambiente e caminhos de vida (Rui, 2016).

Muitas vezes, o "fluxo" expressa uma busca por permanecer vivo frente à morte social (Mauss, 1974) presente no convívio com a vizinhança e a família. No "fluxo", na Cracolândia, a vida se passa como devir: vir a ser, movimento, mudança ou processo. Todos devem "fazer seu corre" e, assim, estar se fazendo a todo tempo. É dessa relação que partem as condições de possibilidade, em que a vida social humana não se separa da do resto da cidade: é parte do que acontece nela, em um processo pelo qual organismos e materiais condicionam a existência uns dos outros. Não haveria 
reciclagem sem o catador de papel que faz seu "corre", nem "maloca" e cachimbo na ausência dos materiais reciclados, que não são processados apenas em uma usina, mas, antecipadamente, na própria rua.

A expressão "estar no corre" significa, ao mesmo tempo, as atividades a serem percorridas pelas pessoas que irão consumir a substância e a realização prévia da ação que irá resultar na possibilidade de uso do crack. Ser "do corre" implica uma autoidentificação. Por sua vez, "fluxo" é, simultaneamente, parte da pessoa e algo a ela pertencente: "eu sou do fluxo" e "eu estou (ou vou para o) no fluxo". Desse modo, "fluxo" é um tropo (no sentido de turn, volta), no qual o sujeito é e está.

Adjacente a essa discussão, cada componente da paisagem urbana aparece como um caminho de transformação, devires, como os apresentados na próxima seção, cujos caminhos se entrelaçam, desdobrando-se na trama da cidade.

\section{A TRANSFORMAÇÃO DE MATERIAIS EM CONSTANTE GERAÇÃO E REGENERAÇÃO}

Propomo-nos agora a descrever como os materiais, componentes ativos das coisas, continuam a se misturar e a reagir em um mundo em formação. Como já adiantamos, iremos nos valer das conclusões de Ingold (2015) quanto ao que seria descrever suas propriedades sob ação do ambiente que a todo tempo ameaça as coisas com a dissolução.

A paisagem da cidade serve de cenário ao craqueiro (Domanico, 2006). De posse da pedra, enquanto prepara e recalibra o cachimbo, o usuário objetiva o próximo trago, mas sua consciência não se detém por aí, ela avança rumo ao "corre". Nesses caminhos erráticos, o craqueiro poderá obter novos fundos, inclusive, para aquisição de mais droga. O binge corresponde a este horizonte que jamais pode ser atravessado; nele se desvenda como a vida pode possuir fins inalcançáveis. O médico Marcelo Clemente (2016: 57, 58) assim descreveu o uso do crack até o esgotamento: "[...] dias sem dormir, em busca do próximo trago, e quando esse trago chegava, se sentiam revigorados, para mais uma maratona em busca do próximo. [...] e só quando chegavam à exaustão eles se permitiam encostar em algum lugar e dormir por algum tempo".

A vida cotidiana dos craqueiros, como qualquervida, é experimental (Ingold, 2015). A experiência com o uso do crack não se limita aos períodos iniciais de uso. Quando iniciam no crack, o fazem, geralmente, acompanhados por pessoas mais experientes. Sua "caminhada" é marcada por mudanças. Cada nova experiência de uso, mesmo que da mesma droga, traz algo de novo: o corpo que envelheceu e se encontra pouco mais ou pouco menos cansado; a chuva que caiu e modificou as

2 | Expressão que diz respeito à viagem do andarilho pela cidade; o mesmo termo se refere aqui à vida de cada condições do ambiente; o sol que esquentou a lona da "maloca", baixa e próxima um: sua "caminhada". da cabeça; seus ocupantes que se revezam ao sabor das possibilidades abertas pela "treta"; um "parça", não visto há algum tempo, com quem se reencontra; um novo conhecido recém-chegado à rua; os itens da parafernália sempre abertos à experimentação. 
A abertura dada pela experimentação constante faz com que possamos dizer que: 1) o usuário de crack é aquele que "faz seu corre"; 2) o "vapor" é quem "está na responsa"; 3) o "nóia" é quem "se deixa levar" ou ser nóia é "se deixar levar"; 4) ser usuário respeitável é "fazer seu corre"; e, nesse sentido, podemos dizer com Ingold (2015: 45) que, para nossos interlocutores, poderia valer a observação de que "...eu sou o que estou fazendo. Eu não sou um agente, mas ramo de atividade". Assim, o conhecimento é forjado pelos caminhos de vida e viagem; locomoção é inseparável de cognição.

A vida social não pode ser ontologicamente distinta de realidades materiais exteriores a ela. Os materiais no "fluxo" estão em contínua transformação, por meio de processos de degradação pela ação da chuva, do vento e do sol. As coisas também. Uma maloca ressoa inteira ao sabor do vento que infla a lona preta como em um veleiro. Aparenta, ao observador menos acostumado à excelência da arquitetura craqueira, estar na iminência de levantar voo a qualquer instante. Os frequentadores do local desempenham um papel central nestas transformações, não apenas os seres humanos envolvidos em reciclar os materiais, mas seus cachorros, animais domésticos destes itinerantes, sem domicílio fixo, também roem, pisoteiam e deitam-se sobre as coisas que se prestem a embalar seu sono canino. Os animais roedores também se fazem presentes, habitando a camada logo abaixo da superfície da cidade e, preferencialmente no período noturno, emergindo à caça de materiais como panos e plástico, além, é claro, dos restos de alimento abandonados pelo chão e ainda não varridos pela chuva para o subsolo pelo acesso disponível através das bocas dos bueiros.

Entre roedores e caninos, estes últimos destacam-se pela empatia e entrosamento com humanos. Porém, há uma história exemplar, contada repetidas vezes pelas rodas de crack do centro, da incompreensão canina das relações entre humanos. Como é comum acontecer nos contatos entre policiais e usuários de crack, a performance de cada ator no desempenho de seu papel aparece ditada pela necessidade de afetar seriedade em uma atividade que poderia ser bem explicada pela popular expressão "enxugar gelo". Os policiais não têm a menor pretensão ou mesmo a intenção de diminuir a venda ou consumo do crack, mas necessitam manter sua presença ostensiva em face das reclamações ou ocorrências, que real ou pretensamente, possam ser associadas com os usuários. Assim, vez ou outra, praticam alguma ação, de caráter, provavelmente, mais exemplar do que punitivo, para lembrar sua existência que, caso contrário, não faria maior diferença à vida do centro da cidade.

Certa feita, ao visualizarem um grupo de usuários de crack próximo ao Vale do Anhangabaú, região central da cidade de São Paulo, policiais militares em patrulha na área, possivelmente sem motivação maior que a simples rotina, iniciaram uma abordagem. Seguindo protocolarmente o roteiro para o qual receberam treinamento, ordenaram que os abordados se levantassem do chão e se colocassem de frente ao muro mais próximo para que pudessem passar por revista. Chuta a perna direita para 
um lado, a esquerda para o outro, passa a mão, ameaça, questiona e os cachimbos vão sendo separados. Todos virados, agora, de frente, mãos para trás como fazem as crianças nas escolas e os milicos nos quartéis, os craqueiros observam seus cachimbos sendo pisados um a um pelos policiais, com vontade só menor que a de pisotear as cabeças dos agraciados pela gentileza policiesca. Porém, o crack, a droga que poderia proporcionar um quê a mais de humilhação e violência ou, até quem sabe, gerar uma "ocorrência" na delegacia, não aparece. Frustração do lado policial e apreensão entre os craqueiros. Mas por que eles estão apreensivos? Aí que entra o cão. Os policiais não perceberam, mas, enquanto executavam a rotina de abordagem, olhos fixos miravam o animal deitado a poucos metros de distância. É que, ao sentirem a aproximação dos enxugadores de gelo, trataram de esconder a droga sob o corpo do animal, confiantes em sua mítica lealdade. Eis que o bicho calmamente se levanta, abre a boca em gostoso bocejar e passa a mover-se no sentido contrário da batida policial. Todos olham incrédulos. Na consciência do proprietário do animal e, infortunadamente, também do crack mal "mocosado"3, vem o pensamento que daria título a esta história: "o cachorro não quis segurar o flagrante". Assim, pela vontade animal, mal ajustada às necessidades humanas impostas pela legislação, essa passagem corriqueira de nossas ruas e da guerra às drogas ficou conhecida como "a história do cachorro que não quis segurar o flagrante". Poderíamos, para este caso, inverter a máxima de Ingold (2015: 57) de que "os seres humanos continuam de onde não humanos param" para: os humanos querem correr quando o não humano se move.

O "flagrante" que o cachorro de nossa estória não quis segurar era também o cachimbo, artefato fundamental que permite fruir a pedra de crack. Nele, o plástico aquecido pelo "Bic" (isqueiro de qualquer marca) derrete e adere ao "fogãozinho". Após esfriar, torna-se duro e não continuará aderindo às mãos do usuário que manipula seu "Boris" (cachimbo para consumo de crack). O plástico só pode participar desta composição por apresentar propriedades diferentes e até mesmo contrárias: ora maleável e próprio à manipulação, ora rígido o suficiente para vedar o topo do "chimbó" (mais uma alcunha dada ao cachimbo). Podemos pensar com Ingold (2015: 65) que "[...] alguns materiais exibem propriedades enquanto estão sendo trabalhados que eles perdem quando o trabalho está feito". A fumaça flui, o plástico adere, o "caninho" (cilindro metálico vazado utilizado nos cachimbos de crack) esquenta, a fumaça condensa e se deposita, adere às paredes do fogãozinho e caninho. $\mathrm{O}$ cachimbo não é fabricado e depois utilizado, mas constantemente aferido e refeito. $A$ "maloca", a mesma coisa, a biqueira também. A pedra, o cachimbo, o usuário, a maloca, a biqueira com materiais em fluxo no "fluxo". O plástico que não adere ao chão e flutua ao sabor do vento - elemento atmosférico passível de desviar a chama do "Bic" e queimar "tudo os dedos" (Clemente, 2016: 60) - se desdobra no ambiente. Pode ser, primeiramente, incorporado pelo morador do "fluxo" a uma maloca, sua ou de alguém a quem deseje ou precise "favorecer". Posteriormente, o mesmo plástico que
3 | O próprio termo "mocosado" (escondido) possui uma origem animal advinda do simpático roedor mocó da família Caviidae, encontrado em áreas pedregosas do Nordeste, onde, para evitar tornar-se alimento humano, costuma se mocosar. Na cidade, 0 mocó também pode se dar a finalidades pedregosas.

4 | Leva este nome por ser comumente uma peça de fogão. É o local sobre o qual ocorre a queima da pedra de crack. Dentro dele se acumula rapa. Quando feito de cobre produz uma rapa branca, muito apreciada. Rapa é material proveniente da sublimação da fumaça de crack em contato com o interio do cachimbo, podendo ser da coloração preta ou branca 
um dia fora uma sacola de supermercado, uma coisa que os craqueiros devolveram à condição de material, poderá ser rasgado em filetes mais ou menos precisos e ajustados à necessidade de vedar a junção do "alumínio" (base perfurada sobre a qual é colocada a cinza e o "trago" em um cachimbo) com o "fogãozinho", depois enrolado e aquecido até derreter e grudar sobre si mesmo. O plástico está no contexto do "fluxo" tanto quanto os seres humanos.

Uma haste de guarda-chuva é colocada, pelo craqueiro, em relação com o "caninho" e "fogãozinho" sob certo campo de atividades comuns no "fluxo", onde pode exercer determinado efeito. $\mathrm{O}$ "raspador" é nomeado pelo efeito que tem na atividade em que está caracteristicamente envolvido, pela sua estória que o usuário conhece e compreende, a fim de usá-lo apropriadamente. O "raspador", haste de alumínio, uma das coisas da qual o guarda-chuva é feito, surge como ferramenta desde o momento em que o objeto guarda-chuva entra no campo de percepção do usuário de crack em uma "caminhada". A maneira de usá-lo leva em conta sua estória pelas conjunções do passado a que os usuários têm acesso, mas também é revelada diante da tarefa a ser executada, seja a retirada da "rapa" de um caninho ou fogãozinho ou ainda da parte interna do alumínio, contrária à face onde se deposita a cinza e onde, também, se acumula a borra proveniente da condensação da fumaça. Em presença de novos materiais, como os inúmeros disponíveis na cidade, que se prestam a servir de peças de cachimbo, o "raspador" será utilizado segundo vertentes de práticas do passado, levadas adiante nos contextos atuais; posto em uso pelas mãos guiadas por traços lembrados de desempenhos pregressos, inscritos em um padrão habitual, usual. Dessa forma, o corpo se lembra. As mãos, pela sua história de vida de práticas passadas, guardam um compêndio de capacidades, mesmo que enegrecidas pela cinza e queimadas pela chama do "Bic". Cinza, chama, pedra e todas as atividades pertinentes à manipulação da parafernália fizeram das mãos, por uma sinergia orgânica, o que elas são; então, põem-se em uso e, por meio de seus gestos habilidosos, contam a biografia do "raspador". Nem parafernália, tampouco as mãos que a manipulam são coisas-em-si-mesmas, independentes do contexto do "fluxo": a "maloca", os recicláveis, a "treta" e o "fluxo", no sentido que este designa a circulação da pedra, mais um de seus significados, são uma história modificada a cada vez que é recontada.

A destreza do craqueiro está na sintonia de seus movimentos, também possibilitados pelo consumo de crack, já que é comum se afirmar que a destreza no trabalho com o cachimbo, que poderíamos designar, neste caso, como o acoplamento multissensorial - o tato dos dedos queimados, a visão, o olfato a sentir os aromas provenientes da prática de se lidar com a pedra de crack, sua fumaça e borra-entre percepção e ação flui melhor sob efeito da pedra. Efeito esse que esconde um propósito de convívio sempre a atravessá-lo, e que frui sob as condições presentes no "fluxo", no habitar e no caminhar, como procuramos descrever na próxima seção. 


\section{HABITAR E CAMINHAR NA PAISAGEM DA CRACOLÂNDIA}

O consumo do crack no "fluxo" permite viver um cotidiano repleto de gestos codificados, práticas e condutas no interior de certo estilo de vida comunitário com suas escolhas diárias e valores subjacentes. Não se busca apenas os efeitos de uma droga, em "relação direta com o contexto mais global da experiência" (Xiberras, 1989: 23), mas estar na presença de outros, entre pares. Existe um propósito de convívio que atravessa o efeito. Portanto, é difícil afirmar se obter a "brisa" seria o principal efeito esperado ou mesmo desejado neste contexto. Isto lança um novo aspecto relativo à intensidade destes efeitos: seriam mais intensos quanto maior a "sintonia"?5 Não são apenas as tragadas de crack em um cachimbo que possuem caráter eminentemente social. Desde a antiguidade que cachimbar ópio se revestia deste aspecto gregário (Escohotado, 1989).

A prática de habitar a Cracolândia ou o "fluxo" faz dos craqueiros parte de um ambiente que vai se fazendo cada vez mais parte deles. Seus sentidos, treinados pela experiência, passam a ver, ouvir e sentir o que lhes importa ao redor. Ao habitar na rua eles vivem, a maior parte do tempo, ao ar livre. Porém, a cidade, com seus edifícios, não permite mirar ao longe o horizonte, como se faz em uma praia quando se admira o nascer do sol a partir do encontro do mar com o céu. O olhar é constantemente detido pelas fachadas dos edifícios. O chão que se pisa é, geralmente, de concreto ou asfalto, à exceção quase exclusiva das praças e terrenos baldios. Os edifícios e demais imóveis possuem, claro, suas entradas, mas o craqueiro que reside ou frequenta a rua percebe reentrâncias invisíveis a olhos destreinados, possíveis "mocós" em aberturas no concreto de viadutos, bueiros, casas e prédios abandonados.

A "maloca" não se deixa objetificar, no sentido de congelar, de afastar-se dos caminhos pelos quais veio a ser. Sua superfície é móvel, o plástico preto, que muitas vezes a encobre, infla ao sabor do vento. Seus materiais estão expostos e o observador, necessariamente imerso na cidade em formação, pode entreter-se em vislumbrá-los e refletir sobre como foram parar ali. Está em um mundo aberto de idas e vindas, continuamente vindo a ser, por processos formativos e transformativos: a maloca é erguida para ser constantemente ajustada. Do concreto surgem estas protuberâncias e na calçada ligam-se substâncias com o meio, numa zona de mistura e entrelaçamento de plásticos, cobertores, madeira, papelão, carrinhos de bebê, entre muitos outros objetos e materiais, todos vivendo na cidade em permeabilidade mútua e vinculante. Por isso o craqueiro liga-se ao transeunte pelo cheiro que, muitas vezes, tenta disfarçar. A fumaça carrega um fio de aroma característico, o "fluxo", que, tanto quanto qualquer rua, está repleta destes fios emanados do cigarro, suor e do "bloco", ligando humanos e não humanos em sua malha; dentro do craqueiro se passa como se a fumaça ressonasse num "tuim", verdadeiro zumbido nos ouvidos que denota efeitos satisfatórios do consumo da pedra. No "fluxo", substâncias se reúnem com o meio na constituição de seres que,

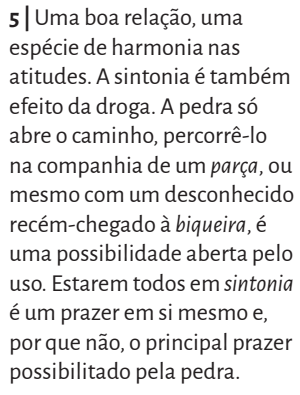
mesmo com um desconhecido recém-chegado à biqueira, é uma possibilidade aberta pelo uso. Estarem todos em sintonia é um prazer em si mesmo e, por que não, o principal prazer possibilitado pela pedra. 
por meio de sua atividade, habitam e participam da costura das texturas da cidade em formas vivas, que cada usuário de crack reúne à sua maneira particular.

$\mathrm{O}$ craqueiro inala constantemente a fumaça proveniente da sublimação da pedra de crack para, depois, poder respirá-la para fora de seu corpo; sua "maloca" no "fluxo", onde a peça da vida é encenada, é animada por um contínuo ir e vir dos "parças", que podem, eventualmente, trazer novos "blocos". A "maloca" é uma experiência. Não é cômodo deixá-la ser banhada pela luz solar. Ao deitar-se sob a lona preta, o teto encontra-se apenas a alguns centímetros do corpo; dá para sentir seu calor.

A Cracolândia como paisagem não pode ser separada das pessoas; ela não se dá simplesmente à observação, descrição e medição empírica independente de quem a constrói. Sua paisagem deve ser dada em relação aos seus habitantes. Os inúmeros significados dali advindos são atribuídos pelos que lá desenvolvem habilidades, adquirem conhecimentos, aparências e identidades. Isto em consonância aos seus movimentos e propósitos, enfim, às suas vidas, de onde extraem o sentido de suas relações. As paisagens variam de acordo com as múltiplas perspectivas de seus habitantes: o passar das estações do ano, os períodos de chuva torrencial, de sol abrasador ou do frio cortante. Este cenário não pode ser abstraído da pessoa que o percebe, da perspectiva de seus habitantes. No verão, as chuvas caem mais fortes e formam poças sob as malocas; as águas correm e levam consigo inúmeros materiais para a sarjeta até adentrarem nos bueiros. Num primeiro momento são águas pretas pela sujeira que, com o prolongar-se da precipitação, vão se tornando cada vez mais transparentes. Com o passar do tempo, coisas semelhantes na paisagem podem ser percebidas de modo diferente, o que faz do tempo menos um objeto de percepção e mais aquilo que nele percebemos.

O usuário de crack é parte da paisagem e foi por ela moldado. Não fosse o asfalto, seus pés não carregariam as marcas de sucessivas feridas cicatrizadas, a pele grossa, endurecida pelo raspar no piso ardente. A crosta enegrecida que, por vezes, cobre a pele, foi adquirida pelo esfolar na sujeira que foi depositada no chão. Os materiais dispostos sobre o chão, na medida em que se esfarelam, passam a confundir-se com ele, porque do asfalto e da calçada também se desprendem partículas, pedras, poeira. Até que fique difícil distinguir entre o que é chão dos materiais que dele se desprendem e nele se depositam, para lá permanecerem à disposição da pele e das roupas do frequentador da Cracolândia, onde poderão se assentar. A poeira de hoje foi o saco plástico de ontem, o maço de cigarros e sua cinza, o alimento deixado cair, os cabelos, pele, unha e excrementos. O solo da Cracolândia é uma zona que, por meio da chuva, do sol, do arrastar dos pés mal calçados ou desnudos, das malocas sucessivamente construídas, desfeitas e refeitas, se forma e é transformada por corpos e materiais que o local põe em movimento. Não à toa a Cracolândia é marcada pelo fluxo dos materiais que compõem e se desprendem de objetos fugazes, como são os cachimbos, em constante e ininterrupto devir. $\mathrm{O}$ asfalto de suas ruas e as calçadas 
são testemunhas da vivacidade das forças e relações de uma cidade-tempo, onde o usuário de crack percebe e age.

A Cracolândia nunca está completa ou acabada, é constantemente tecida a partir das linhas vitais de componentes humanos e não humanos variados, enquanto costuram seus caminhos pelo emaranhado de relações em que vão se enredando. Pessoas e coisas são identificáveis pelos caminhos de onde vieram e pelos quais prosseguem indo. São indissociáveis dos movimentos que as trouxeram ali e de seus relacionamentos em prática, numa malha relacional de enlaces e desenlaces. O conhecimento, para estas pessoas, é adquirido também pelos caminhos do movimento, na "caminhada" como uma trilha através de uma malha.

O crack possui um "espírito andarilho" que faz o corpo peregrinar, perambularpela cidade. O usuário habita a cidade como peregrino, numa vida que se desdobra ao longo de caminhos. $\mathrm{O}$ "parça" é produto do encontro de trilhas vitais que se entrelaçam fortemente e vinculam-se em um nó de maior densidade. O crack impulsiona os encontros na cidade e torna-se um remédio contra a solidão. A "maloca" proporciona um ambiente convidativo ao consumo de crack, onde se podem formar nós de grande densidade a partir dos fios atados por linhas de peregrinação na "caminhada". O "corre", a "caminhada", impulsionados pelo "espírito andarilho" do crack, incentivam o usuário a prender-se a outras linhas em outros lugares bosquejados pelo movimento, formando uma malha ao longo da qual estas pessoas vivem suas vidas nas ruas e calçadas da cidade.

O usuário está constantemente em movimento; não deseja ser considerado um "parasita" (pessoa que não faz seu "corre" e usa crack a expensas de outros usuários), faz seu "corre", usa a droga do "espírito andarilho", "é do crack", "é do movimento". Usar crack é mais que estar em movimento; o usuário na cidade, tal qual o peregrino, é seu movimento, que, para ser sustentado, depende de um engajamento ativo com a rua, com o "fluxo", com a Cracolândia, enfim, com o consumo do crack. A "caminhada" nunca encontra um ponto final, mesmo no descanso sempre haverá outro lugar para ir. Estar na "correria" é um modo de ser, de estar no mundo. Mais que ocupar uma área, o usuário de crack habita linearmente e, talvez por isso, os que têm maior dificuldade em se afastar do "fluxo" causem algum espanto.

Como o morador de rua lida com a exclusão sob este ponto de vista? Primeiro, é difícil caracterizá-lo como excluído da sociedade, visto que reside no ambiente da cidade interagindo com a paisagem: a calçada, o muro, a marquise, o viaduto, a grade. É, também, forçado a interagir com agentes públicos e privados como: seguranças, policiais, faxineiros de estabelecimentos comerciais, porteiros, operacionais da limpeza pública, missionários e pregadores. Por vezes, pode procurar estes mesmos atores na busca por satisfazer alguma necessidade de abrigo, alimento, vestimenta ou uma simples companhia. Por outras, pode ser por eles contatado e por uma gama de outros habitantes que se interessem, por qualquer motivo (que pode ir da caridade ao desejo por informações sobre aquisição de drogas) em interagir com ele. Porém, o maior prazer parece 
estar na companhia, não de outsiders, mas de pares, "parças" em situação semelhante. Possivelmente, porque entre os que assumem a mesma forma se possa ter um nome (vulgo) e um endereço (maloca). Para o "Zé Povinho", o morador de rua que, aparentemente, está sob efeito do crack, é um genérico zumbi. É-lhe atribuída uma condição inferior às consideradas por Ingold (2015) para designar a pessoa sem nome e endereço, como é a do "vagabundo", do "fugitivo" e do "selvagem"; e mesmo a animalidade pode Ihe ser negada. $O$ animal é o ser animado, o que possui anima ou fôlego vital e é capaz de responder ao ambiente que o envolve, inverso do zumbi.

As histórias de violência assassina praticada pelas pessoas que habitam ou frequentam a Cracolândia são contadas pela mídia e transmitidas à exaustão nos momentos de pânico moral em torno do crack; ajudam a criar uma visão totalizante daquele território e seus ocupantes. Imagens reais para compor uma descrição fantástica, com o intuito de unir o país "através da obscuridade epistemológica do espaço da morte" (Taussig, 1993: 138), onde a tortura e o terror praticados pelos agentes públicos e governantes se tornam não só justificáveis como falsamente necessários. Violência sobre pessoas cuja forma de agir pode, paradoxalmente, passar a impressão de certo alheamento do mundo e, ainda assim, capaz de apavorar um desavisado que as cruzar numa calçada.

Ingold (2015) descreveu o ato de caminhar em público, delineado por Goffman (1971), como uma atividade quase predominantemente visual em que o transeunte anda como que envolto por uma casca ovalada, estreita nas laterais e alongada à frente. Para deslocar-se em meio a outros pedestres, calcula constantemente os ajustes necessários aos trajetos das demais pessoas e executa movimentos bruscos, quando necessário, em uma socialidade imediatamente sensível aos movimentos dos outros e às pequenas obstruções do chão. O usuário de crack irá respeitar menos estas regras, quanto mais imerso esteja em uma "caminhada" ou "sonhando acordado".

É usual, na rua, se ter um vulgo que é atribuído segundo características pessoais de aparência física, temperamento, origem, e é como termina conhecido pelos pares. Pode possuir, ou não, uma "maloca". Esta também tem sua localização na cidade, que permanece, muitas vezes, a mesma no decorrer de anos. Esta localidade pode ser, por exemplo, o "fluxo", porque lá existe uma atividade de venda de drogas que provoca a ida e vinda de pessoas e objetos e ela é seu nexo. As pessoas que lá possam vir a habitar são, muitas vezes, usuárias fortes de crack, porque passam ali seus dias se movimentando entre "malocas", participando da "treta" e outros deslocamentos em busca de fundos, caracterizando certos padrões de atividades que fazem delas o que elas são ao se desdobrarem na cidade em formação permanente. A alcunha de craqueiro dá a dimensão do que a pessoa é pelo que ela faz. Ser "do crack"é, geralmente, desdobrar-se pela cidade na "caminhada", muito além de fumar pedra.

Que forças serão capazes de misturar e fundir materiais tão heterogêneos na geração das coisas presentes na Cracolândia? Não se trata de imprimir forma à 
matéria inerte, mas de intervir nas correntes de material que geram as formas. Seguir os materiais que são misturados para que uma "maloca" seja gerada nos permite perceber como eles não são passivos ou subservientes aos projetos humanos, e como esta habitação demanda um esforço incessante para se manter íntegra face aos ataques do meio impetrados pelo vento, sol, chuva, insetos, roedores e, é claro, pela desordem causada por visitantes e transeuntes. A "maloca" não é um fato consumado, como um objeto, mas um acontecimento, um entrelaçamento passageiro de materiais em movimento, uma coisa. A "maloca" e o cachimbo são improvisados à medida que a vida prossegue pelos caminhos do mundo: "caminhada". Na figura 3, um exemplo de "maloca".

A "maloca" e o "mocó" nos fazem pensar sobre o que funda as relações entre ser humano e espaço, em como elasfuncionamecomose transformam; em o que é geral e o que é particular. A dimensão espacial da construção do usuário de crack se apresenta seja ele: 1) morador fixado de modo mais permanente em uma biqueira ou mesmo na Cracolândia; 2) frequentador assíduo de certos "mocós" espalhados pela cidade; 3) peregrino mais afeito

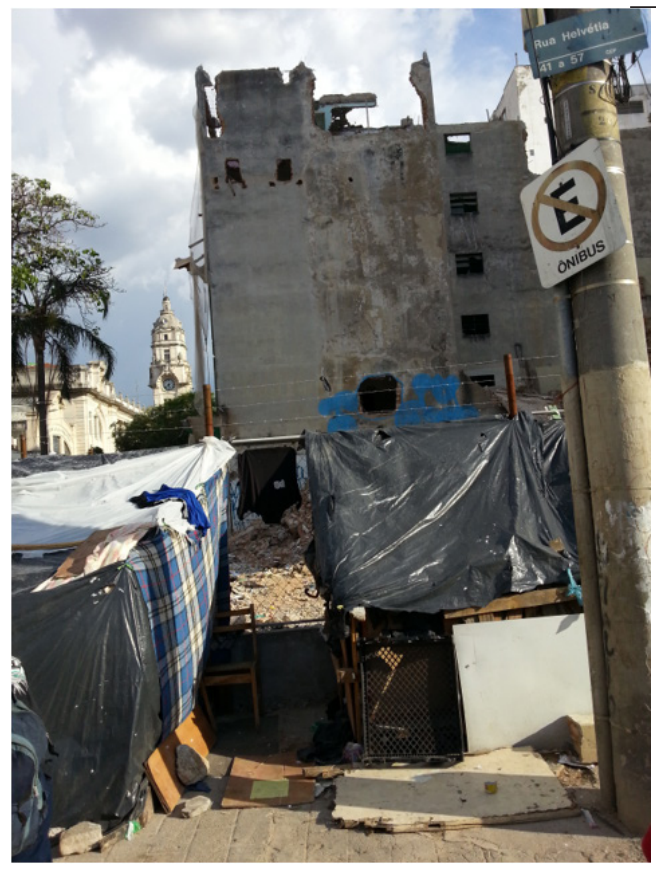
ao ar livre e a transitar pelas calçadas, escolhendo esta ou aquela marquise onde possa descansar quando sinta necessidade.

A unificação da paisagem urbana, feita pela arquitetura moderna, ignorou o contexto de cada cidade, como se proposta fosse para um ser humano dotado de necessidades universais (Rui, 2014b). Uma arquitetura funcionalista, que se utiliza de técnicas industriais voltadas a baratear ao extremo as construções por meio de ganhos de escala produzidos pela homogeneização. Na maloca, as aspirações em termos de âmbito construído são definidas, muitas vezes, por um ente único. O destinatário da habitação é, também, seu construtor/projetista: apesar da pobreza e dos dramas ali presentes, a "maloca", de certo modo e provocativamente, pode ser vista como uma utopia urbana materializada na moradia de rua.

Ao final dessa caminhada de pesquisas e relacionamentos que este artigo busca delinear, acreditamos que pudemos deixar mais claras as relações e forças que se estabeleciam para que as rodas de crack se espalhassem pelo bairro da Luz. Além disso, tentamos dissertar um pouco sobre o que nos conta a categoria "fluxo" e sobre quais relações estabelecidas no "fluxo" possibilitavam habitar aquele espaço. Sempre
Figura 3

Maloca localizada na rua Helvetia quase esquina com alameda Cleveland Fonte: Coleção particular do autor. 
pensando com Ingold, tentamos mostrar como seria possível lidar com forças que poderiam implicar falta de capacidade de vida, sendo que as pessoas que habitam o "fluxo" acabam por construir outras formas de viver.

Os locais de uso do crack são percebidos como espaços vinculados exclusivamente ao consumo da substância. Porém, o convívio com nossos interlocutores nos permitiu perceber que também havia uma participação comum na roda de crack que superava sua heterogeneidade, como parte do campo de possibilidades próprio à cidade grande, onde trajetórias e trilhas podem se cruzar. A experiência de usar crack na calçada permite certas interações, travessias sociológicas, possivelmente difíceis de se darem sem este aglutinador. Ao se tornar morador da Cracolândia ou frequentador cotidiano do "fluxo", dele se ausentando o mínimo necessário para algum "corre" em busca de fundos para aquisição de crack, a capacidade de transitar pelas diversas províncias de significado da cidade, no entanto, diminui. Deparamo-nos com pessoas há anos sem abandonar a área restrita do "fluxo", um local de imensa agitação.

O consumo do crack no "fluxo" permite viver um cotidiano repleto de gestos codificados, práticas e condutas no interior de certo estilo de vida, com suas escoIhas diárias e valores subjacentes. O craqueiro não busca apenas os efeitos de uma droga, mas estar na presença de outros, em condições semelhantes e que entendam os códigos. Existe um propósito de convívio que atravessa o efeito de fumar crack. $\mathrm{O}$ craqueiro e seus parças não se distinguem de sua "caminhada", nem de suas relações estendidas ao longo de múltiplas trilhas entrelaçadas no ambiente de emaranhamento. A "caminhada" é uma forma de habitar o mundo, de costurar a própria linha de vida e contribuir na sua trama em constante movimento. O consumo do crack impulsiona os encontros na cidade. O craqueiro traça itinerários e constrói novos modos de estar no mundo. Substâncias, objetos, presenças, encontros, caminhadas, itinerários que, a despeito da gravidade da situação ali presente e dos dramas sociais que envolvem, constroem a atratividade e resiliência do "fluxo".

Ygor Diego Delgado Alves é antropólogo graduado e mestre em Ciências Sociais pela Pontifícia Universidade Católica de São Paulo; doutor em Antropologia pela Universidade Federal da Bahia; pós-doutorando em Saúde Coletiva pela UNIFESP, com auxílio financeiro FAPESP, CAPES e bolsa Pós-Doutorado Júnior pelo CNPQ. Áreas de atuação: Antropologia da Saúde, Saúde Coletiva, Antropologia Urbana e Antropologia das Drogas.

Pedro Paulo Gomes Pereira é livre-docente pela Universidade Federal de São Paulo (2013). Professor Associado da Universidade Federal de São Paulo. Professor do Programa de Pós-Graduação em Saúde Coletiva da Universidade Federal de São Paulo. 
Coordenador do Quereres - Núcleo de Pesquisa em Diferenças, Direitos Humanos e Saúde. Áreas de atuação: corpo, saúde, doença.

FINANCIAMENTO: Esse artigo teve financiamento de Bolsa CNPQ (Conselho Nacional de Desenvolvimento Científico e Tecnológico) pós-doutorado júnior [150261/2019-5].

\section{CONTRIBUIÇÃO DE AUTORIA}

Ygor Diego Delgado Alves contribuiu para concepção e análise, redação, discussão de resultados, realização do campo etnográfico e revisão do artigo. Pedro Paulo Gomes Pereira contribuiu para concepção e análise, redação, discussão de resultados, realização do campo etnográfico e revisão do artigo.

\section{REFERENCIAS BIBLIOGRÁFICAS}

ADERALDO, G.; FAZZIONI, N. 2012.

"Choro e samba na Luz: etnografia de práticas de lazer e trabalho na R. Gal. Osório". Ponto Urbe, n. 11: 1-19. https:// doi.org/10.4000/pontourbe.1159

ADORNO, R. et. al. 2013. "Etnografia da cracolândia: notas sobre uma pesquisa em território urbano". Saúde \& Transformação Social/Health \& Social Change, n. 4(2): 4-13.

ADORNO, R. et. al. 2014. "Amarga delícia: Experiências de consumo de crack na região central de São Paulo (BR)". Revista Inter-Legere, n. 15: 87-109.

ALVES, Y. D. D. 2017. Jamais fomos zumbis: contexto social e craqueiros na cidade de São Paulo. Salvador, EDUFBA. https:// doi.org/10.7476/9788523218591

BECKER, H. S. 2009. Outsiders: estudos de sociologia do desvio. Rio de Janeiro, Zahar.

BOURCOIS, P. 2006. In search of respect: selling crack in El Barrio. Nova lorque, Cambridge University Press.

BOURGOIS, P.; SCHONBERG, J. 2009.

Righteous dopefiends. Los Angeles, University of California Press.
CALIL, T. C. 2015. Condições do lugar: Relações entre saúde e ambiente para pessoas que usam crack no bairro da Luz, especificamente na região denominada cracolândia. São Paulo, dissertação de mestrado, Universidade de São Paulo.

CHAVES, T. V. et. al. 2011. "Crack cocaine craving: behaviors and coping strategies among current and former users". Revista de Saúde Pública, n. 45(6): 1168-1175. http://dx.doi. org/10.1590/So034-89102011005000066

CLEMENTE, M. 2016. A Cracolândia dia a dia. São Paulo, Giostri.

COSTA, G.; LIMA, H. 2015. “A loucura atrás das grades: recorte histórico da segregação dos indesejáveis". Revista Transgressões, n. 1(1): 64-88.

COSTA Jr, C.; SOUZA, G. 2014. Vizinhos da Cracolândia: a memória de quem viu um mundo paralelo se erguer na região da Luz. São Paulo, Edição dos Autores.

DA SILVA, S.; ADORNO, R. 2013. “A etnografia e o trânsito das vulnerabilidades em territórios de resistências, registros, narrativas e reflexões a partir da Cracolândia". Saúde \& Transformação Social/Health \& Social Change, n. 4(2): 21-31. 
DOMANICO, A. 2006. "Craqueiros e Cracados: bem-vindo ao mundo dos noias!": estudo sobre a implementação de estratégias de redução de danos para usuários de crack nos cinco projetos-piloto do Brasil. Salvador, tese de doutorado, Universidade Federal da Bahia.

ESCOHOTADO, A. 1989. História general de las drogas. Madrid, Alianza Editorial.

FAVRET-SAADA, J. 2017. "Ser afetado". Cadernos de campo, n. 13: 155-161. https://doi. org/10.11606/issn.2316-9133.v13i13p155-161

FERNANDEZ, O. 2007. Coca light?: usos do corpo, rituais de consumo e carreiras de "cheiradores" de cocaína em São Paulo. Salvador, tese de doutorado, Universidade Federal da Bahia.

FROMM, D. 2017. “Percursos e refúgios urbanos. Notas sobre a circulação de usuários de crack pela trama institucional da Cracolândia de São Paulo". Ponto Urbe. Revista do núcleo de antropologia urbana da USP, 21: 1-16. https://doi. org/10.400o/pontourbe.3604

FRÚGOLI JR. H.; CAVALCANTI, M. 2013. "Territorialidades da(s) cracolândia(s) em São Paulo e no Rio de Janeiro". Anuário Antropológico, n. 2, 73-97. https://doi.org/10.4000/aa.561

HERZFELD, M. 1997. Cultural Intimacy: Social Poetics in the Nation State. New York, Routledge.

INCOLD, T. 1991. "Become persons: consciousness and sociality in human evolution". Cultural Dynamics, n. 4(3): 355-378.

INCOLD, T. 2002a. The perception of the environment: essays on livelihood, dwelling and skill. London, Routledge.

INCOLD, T. 2003. "A evolução da sociedade". In: FABIAN, A. C. (Org.). Evolução: sociedade, ciência e universo. Bauru, EDUSC, pp. 107-131.
INGOLD, T. 2015. Estar vivo: ensaios sobre movimento, conhecimento e descrição. Petrópolis, Vozes.

JORGE, M. S. B. et. Al. 2013. "Ritual de consumo do crack: aspectos socioantropológicos e repercussões para a saúde dos usuários". Ciência \& Saúde Coletiva, n. 18(10): 29092918. https://dx.doi.org/10.1590/S141381232013001000015. http://dx.doi. org/10.1590/S1413-81232013001000015

MacRAE, E.; SIMÕES, J. A. 2000. Rodas de fumo: o uso da maconha entre camadas médias urbanas. Salvador, EDUFBA.

MAGALHÃES, T. 2015. Campos de disputa e gestão do espaço urbano: o caso da 'cracolândia' paulistana. São Paulo, tese de doutorado, Universidade de São Paulo.

MAGNANI, ]. G. C. 2003. Festa no pedaço: cultura popular e lazer na cidade. São Paulo, EDUNESP/Hucitec. https://doi. org/10.4000/pontourbe.2041

MACNANI, J. G. C. 2008. Na metrópole: textos de Antropologia Urbana. São Paulo, EDUSP.

MAGNANI, J. G. C. 2014. "O Circuito: proposta de delimitação da categoria". Ponto Urbe. São Paulo, n. 15: 1-13.

MALHEIRO, L. 2012. "Tornando-se um usuário de crack". In NERY FILHO, A. et. al. As drogas na contemporaneidade: perspectivas clínicase culturais. Salvador, EDUFBA, pp. 79-100.

MALHEIRO, L. S. 2013. "Entre sacizeiro, usuário e patrão: Um estudo etnográfico sobre consumidores de crack no Centro Histórico de Salvador". In: MacRAE, E.; TAVARES, L. R.; NUÑES, M. E. Crack: contextos, padrões e propósitos de uso. Salvador, EDUFBA, pp. 154-227.

MALVASI, Paulo Artur. 2012. Interfaces da vida loka: um estudo sobre jovens, tráfico de drogas e violência em São Paulo. São Paulo, tese de doutorado, Universidade de São Paulo. 
MAUSS, M. 1974. “Efeito físico no indivíduo da ideia de morte sugerida pela coletividade". In MAUSS, M. 1974. Sociologia e antropologia. São Paulo, EDUSP, pp. 185-208.

MERCANTE, M. 2012. Imagens de cura: ayahuasca, imaginação, saúde e doença na barquinha. Rio de Janeiro, FIOCRUZ.

RAUPP, L. M.; ADORNO, R. 2015. "Jovens em situação de rua e usos de crack: um estudo etnográfico em duas cidades". Revista Brasileira Adolescência e Conflitualidade, n. 4: 52-67. https://doi. org/10.17921/2176-5626.n4p\%25p

ROMANINI, M., e ROSO, A. 2014.

"Midiatização do crack e estigmatização: corpos habitados por histórias e cicatrizes". Interface: Comunicação, Saúde, Educação, n. 18(49): 363-376. http://dx.doi. org/10.1590/1807-57622013.0138

RUI, T. 2012. "Vigiar e cuidar: notas sobre a atuação estatal na 'Cracolândia'". Revista Brasileira de Segurança Pública, n. 6(2): 336-351.

RUI, T. 2014a. “Usos da 'Luz' e da 'Cracolândia': etnografia de práticas espaciais". Saude soc., n. 23(1): 91104. http://dx.doi.org/10.1590/ S0104-12902014000100007

RUI, T. 2014b. "A cidade, desde as cracolândias. Novos Debates". Fórum de debates em Antropologia (ABA), n. 1: 52-57.

RUI, T. 2016. "Fluxos de uma territorialidade: duas décadas de 'Cracolândia' (19952014)”. In: KOWARICK, L.; FRUCOLI Jr,
H. (Orgs.). Pluralidade Urbana em São Paulo: vulnerabilidade, marginalidade, ativismos sociais. São Paulo, Ed. 34/FAPESP, pp. 225-248.

SILVA, Regina Coeli Machado e. 2011. "A teoria da pessoa de Tim Ingold: mudança ou continuidade nas representações ocidentais e nos conceitos antropológicos?". Horiz. antropol., n. 17(35): 357-389. http://dx.doi. org/10.1590/So104-71832011000100012 SIMMEL, G. 1971. On individuality and social forms. Chicago, University of Chicago Press.

STRATHERN, M. 1999. Property, substance, and effect: anthropological essays on persons and things. London, Athlone Press.

TAUSSIG, M. 1993. Xamanismo, Colonialismo e o Homem Selvagem. Rio de Janeiro, Paz e Terra.

URIARTE, U. M. 2012. "O que é fazer etnografia para os antropólogos". Ponto Urbe. Revista do núcleo de antropologia urbana da USP, n. 11: 1-13. https://doi.org/10.400o/pontourbe.300

VELHO, G. 1999. Projeto e metamorfose: antropologia das sociedades complexas. Rio de Janeiro, Zahar.

XIBERRAS, M. 1989. A sociedade intoxicada. Lisboa, Instituto Piaget.

\section{MATERIAL CONSULTADO}

PMSP. 16 jan. 2015. Secretaria Especial de Comunicação. Programa "De Braços Abertos" completa um ano com diminuição do fluxo de usuários e da criminalidade na região. São Paulo. Disponível em: http://www.capital.sp.gov.br/noticia/ programa-de-bracos-abertos-completaum-ano-com. Acesso em: 25 ago. 2017.

Recebido em 30 de setembro de 2018. Aceito em 29 de julho de 2020. 